\title{
APLIKASI OPERASI MATRIKS PADA PERANCANGAN SIMULASI METODE HILL CIPHER MENGGUNAKAN MICROSOFT EXCEL
}

\author{
Endaryono $^{1}$, Nurfidah Dwitiyanti ${ }^{2}$, Heri Satria Setiawan ${ }^{3}$ \\ Program Studi Teknik Informatika, Universitas Indraprasta PGRI ${ }^{1,2,3}$ \\ endaryono612@gmail.com,nurfidah.pulungan@gmail.com, heri.satria71@yahoo.com
}

Submitted January 28, 2021; Revised July 31, 2021; Accepted August 2, 2021

\begin{abstract}
Abstrak
Satu dari beberapa algoritma dalam kriptografi adalah metode Hill Cipher. Metode ini dalam melakukan pengacakan isi pesan menggunakan kunci sandi berupa matriks berordo mxm.. Produk dalam penelitian ini berupa perancangan simulasi untuk menjelaskan bagaimana suatu pesan plaintext diubah menjadi cipher text dengan proses enkripsi dan dekripsi dan sebaliknya dari ciphertext menjadi paintext melalui operasi perkalian dan invers matriks menggunakan Microsoft Excel (MS Excel). Dalam penelitian ini digunakan matriks berordo $2 \times 2$ dan modulo 26. Pada rancangan simulasi ini ditunjukkan bagaimana proses kerja secara visual setiap langkah dalam proses pengubahan isi pesan pada metode Hill Cipher. Hasil penelitian ini berupa rancagan simulasi metode Hill Cipher dengan menggunakan apikasi Microsoft Excel yang digunakan sebagai media pembelajaran oleh masyarakat khususnya mahasiswa dan dosen untuk meningkatkan pemahaman dan memperluas cakrawala pemikiran tentang metode Hill Cipher dalam perkuliahan kriptografi.
\end{abstract}

Kata Kunci : Hill Cipher, kriptografi, matriks, perkalian, invers

\begin{abstract}
One of several algorithms in cryptography is the Hill Cipher method. This method is used in randomizing the contents of the message using a password key in the form of a matrix with the order MXM. The product in this research is a simulation design to explain how a plaintext message is converted into cipher text with encryption and decryption processes and vice versa from ciphertext to paintext through multiplication and inverse matrix operations. using Microsoft Excel (MS Excel). In this study, a matrix with order $2 x 2$ and modulo 26 was used. This simulation design shows how the work process visually for each step in the process of changing the message content in the Hill Cipher method. The results of this study are in the form of a simulation of the Hill Cipher method using the Microsoft Excel application which is used as a learning media by the community, especially students and lecturers to increase understanding and expand ideas about the Hill Cipher method in lectures.
\end{abstract}

Key Words : Hill Cipher, cryptography, matrix, multiplication, inverse

\section{PENDAHULUAN}

Komunikasi dan informasi memegang peranan penting. Media komunikasi dan informasi pun berkembang dengan pesat. Seseorang atau suatu kelompok yang menguasi informasi dan media informasi maka ia adalah pemenang.

Dalam suatu informasi ada banyak informasi yang bersifat khusus dan bukan konsumsi untuk masyarakat luas. Beberapa informasi bersifat terbatas dan hanya untuk otoritas tertentu yang dapat mengaksesnya. Dibutuhkan keamanan untuk menjaga kerahasiaan informasi agar tidak sampai ke pihak lain. Metode kriptografi dan algoritma persandian perlu dilakukan agar isi pesan terlindungi dengan baik. 
Secara etimologi, kriptografi berasal dari bahasa Yunani yang terdiri dari kata cryptos artinya menyembunyikan rahasia dan kata graphein yang artinya menulis. Kriptografi adalah bagian dari matematika yang membahas tentang keamanan suatu pesan, otensifikasi data, validitas dan kerahasiaan suatu data. Kriptografi dapat pula dianggap suatu seni dalam keamanan informasi [1].

Komponen kriptografi terdiri atas:

a. Plaintext, pesan asli, dapat dipahami.

b. Ciphertext, pesan acak, sulit atau tak bisa dipahami.

c. Key, kunci yang digunakan dalam kriptografi

d. Algorithma atau cipher berupa urutan kerja pada aturan enkripsi (enchipering) dan dekripsi (dechipering) [2]

Proses dasar dari kriptografi terdiri dari:

a. Enkripsi, proses penyandian, mengubah kode atau pesan yang dimengerti (plaintext) menjadi kode atau pesan yang tidak bisa dipahami (chipertext)

b. Proses kebalikannya disebut deskripsi, mengubah cipherteks menjadi plainteks.

c. Proses enkripsi dan dekripsi membutuhkan mekanisme dan kunci (key) dalam suatu sistem yang disebut cipher. [3]

Ilustrasi kerja operasi kriptografi dapat dilihat pada gambar 1[4]

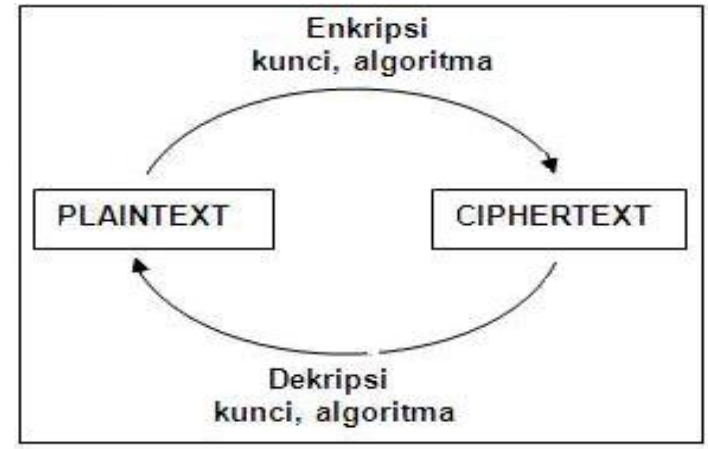

Sumber : [4]

Gambar 1. Operasi Kriptografi
Metode Hill Cipher merupakan satu dari beberapa metode dalam kriptografi. Metode ini tidak berdasarkan pada penggantian setiap abjad yang sama pada plaintext dengan abjad lainnya yang sama pada ciphertext. Metode ini menggunakan kunci dengan suatu matriks ordo mxm. Banyak hal yang dapat dilakukan pada sebuah matriks. Diantaranya perkalian matriks, mencari determinan matriks, menentukan invers matriks, trace matriks, dan lain sebagainya [5].

Teori aritmatika modulo yang diterapkan terhadap matriks nxn merupakan dasar dari konsep kerja Hill Chiper. [6] Misalkan a adalah bilangan bulat dan $\mathrm{m}$ adalah bilangan bulat positif. Operasi $a \bmod m$ (dibaca a modulo $\mathrm{m}$ ) memberikan sisa $\mathrm{r}$ jika a jika dibagi dengan $\mathrm{m}$. Notasinya ditulis: $\mathrm{a} \bmod \mathrm{m}=\mathrm{r}$ mempunyai arti $\mathrm{a}=$ $\mathrm{mk}+\mathrm{r}$, dengan $0 \leq \mathrm{r}<\mathrm{m}$ dan $\mathrm{k}$ suatu kelipatan. Bilangan $\mathrm{m}$ disebut modulus atau modulo. Hasil aritmetika modulo $\mathrm{m}$ yaitu $r$ terletak di dalam himpunan $\{0,1,2$, $\ldots, \mathrm{m}-1\}$. Beberapa contoh operasi modulo:

a. $23 \bmod 5=3$ karena $23=5 \cdot 4+3$

b. $17 \bmod 8=1$ karena $17=8 \cdot 2+1$

c. $14 \bmod 9=5$ karena $14=9 \cdot 1+5$ dan seterusnya [7].

Penelitian lain yang serupa dalam pembahasan metode Hill Cipher antara lain:

a. Penerapan Algoritma Hill Cipher Dan Least Significant Bit (LSB) Untuk Pengamanan Pesan Pada Citra Digital, [8]

b. Kriptografi Citra Digital Menggunakan Algoritma Hill Cipher Dan Affine Cipher Berbasis Android,[9]

c. Kriptanalisis Hill Cipher terhadap Known Plaintext Attack Menggunakan Metode Determinan Matriks Berbasis Android, [10]

d. Implementasi Hill Cipher Pada Citra Menggunakan Koefisien Binomial Sebagai Matriks Kunci [11]. 
Penelitian ini membahas tentang proses kerja algoritma Hill Cipher menggunakan operasi perkalian dan invers matriks pada aplikasi Microsoft Excel (MS Excel). Pemilihan aplikasi MS Excel ini didasarkan karena aplikasi MS Excel luas penggunaannya, mudah pelaksanaannya, dan banyak kalangan yang sudah terbiasa atau familiar dengan aplikasi ini. Pada penelitian ini aplikasi MS Excel dapat dimanfaatkan untuk menunjukkan cara kerja algoritma Hill Cipher dalam kriptografi.

Tujuan penelitian ini adalah membuat suatu rancangan simulasi proses kerja enkripsi dan dekripsi algoritma Hill Cipher dengan menggunakan Microsoft Excel yang dapat menjadi pilihan media pembelajaran kriptografi oleh masyarakat khususnya mahasiswa dan dosen.

\section{METODE PENELITIAN}

Metode yang digunakan adalah:

a. Studi Literatur

Dilakukan kajian-kajian teori kriptografi dan matematika berkaitan dengan aplikasi berdasarkan buku-buku ilmiah dan jurnal

b. Pemodelan Sistem

Pemodelan sistem dilakukan agar tergambar bagian-bagian dari sistem, langkah dan alur kerja serta operasi dari setiap bagian.

c. Perancangan Aplikasi dalam simulasi

Selanjutnya dilakukan rancangan simulasi dengan menerapkan teori dan pemodelan yang telah dibuat.

\section{HASIL DAN PEMBAHASAN \\ Proses Enkripsi}

Formula matematis dalam proses enkripsi adalah: $\mathrm{C}=\mathrm{PK}$ [8]

$\mathrm{C}=$ Matriks ciphertext atau matriks pesan yang sudah diacak

$\mathrm{P}=$ Matriks plaintext atau matriks dari pesan asli
$\mathrm{K}=$ Matriks kunci atau matriks key yaitu matriks dari kunci yang digunakan dalam proses enkripsi.

Secara lengkap, operasi matematika dalam proses enkripsi sebagai berikut:

$\mathrm{C}_{11}=\left(\mathrm{P}_{11} \cdot \mathrm{K}_{11}+\mathrm{P}_{12} \cdot \mathrm{K}_{21}\right) \bmod 26$

$\mathrm{C}_{12}=\left(\mathrm{P}_{11} \cdot \mathrm{K}_{12}+\mathrm{P}_{12} \cdot \mathrm{K}_{22}\right) \bmod 26$

$\mathrm{C}_{21}=\left(\mathrm{P}_{21} \cdot \mathrm{K}_{11}+\mathrm{P}_{22} \cdot \mathrm{K}_{21}\right) \bmod 26$

$\mathrm{C}_{22}=\left(\mathrm{P}_{21} \cdot \mathrm{K}_{12}+\mathrm{P}_{22} \cdot \mathrm{K}_{22}\right) \bmod 26$

Formula matematis ini diterapkan dalam proses enkripsi metode Hill Cipher sebagai berikut:

1. Masukkan P atau pesan asli (plaintext).

2. Pesan diubah menjadi bilangan atau angka yang nilainya dari 0 sampai dengan 25 atau modulo 26. Pengubahan teks menjadi angka-angka atau bilangan berdasarkan penerapan fungsi bijektif.

3. Semua bilangan selanjutnya disusun menjadi beberapa blok atau partisi membentuk suatu matriks dengan ordo $m \times 2$. Hasil dari langkah ini berupa matriks pesan atau $\mathbf{M p}$.

4. Masukkan kunci untuk persandian berupa matriks persegi ordo $2 \times 2$. Selanjutnya mtriks ini disebut dengan matriks kunci atau Mk

5. Lakukan perkalian antara matriks pesan (Mp) ordo $\mathrm{mx} 2$ dengan matriks kunci (Mk) ordo 2x2. Hasilnya adalah matriks Cipher (Mc) ordo $\mathrm{mx} 2$.

Persamaan matematika: $\mathbf{M c}=\mathbf{M p}$. Mk.

6. Lakukan operasi aritmatika modulo 26 pada matriks cipher Mc sehingga semua anggota atau elemen matriks cipher Mc dimulai dari 0 sampai dengan 25 .

7. Susun kembali partisi-partisi atau blokblok pada matriks cipher Mc dalam susunan mendatar atau horizontal.

8. Ubah bilangan-bilangan pada susunan horizontal menjadi abjad dengan menggunakan fungsi bijektif.

Tampilan muka input dan output proses enkripsi dapat dilihat pada gambar 2 


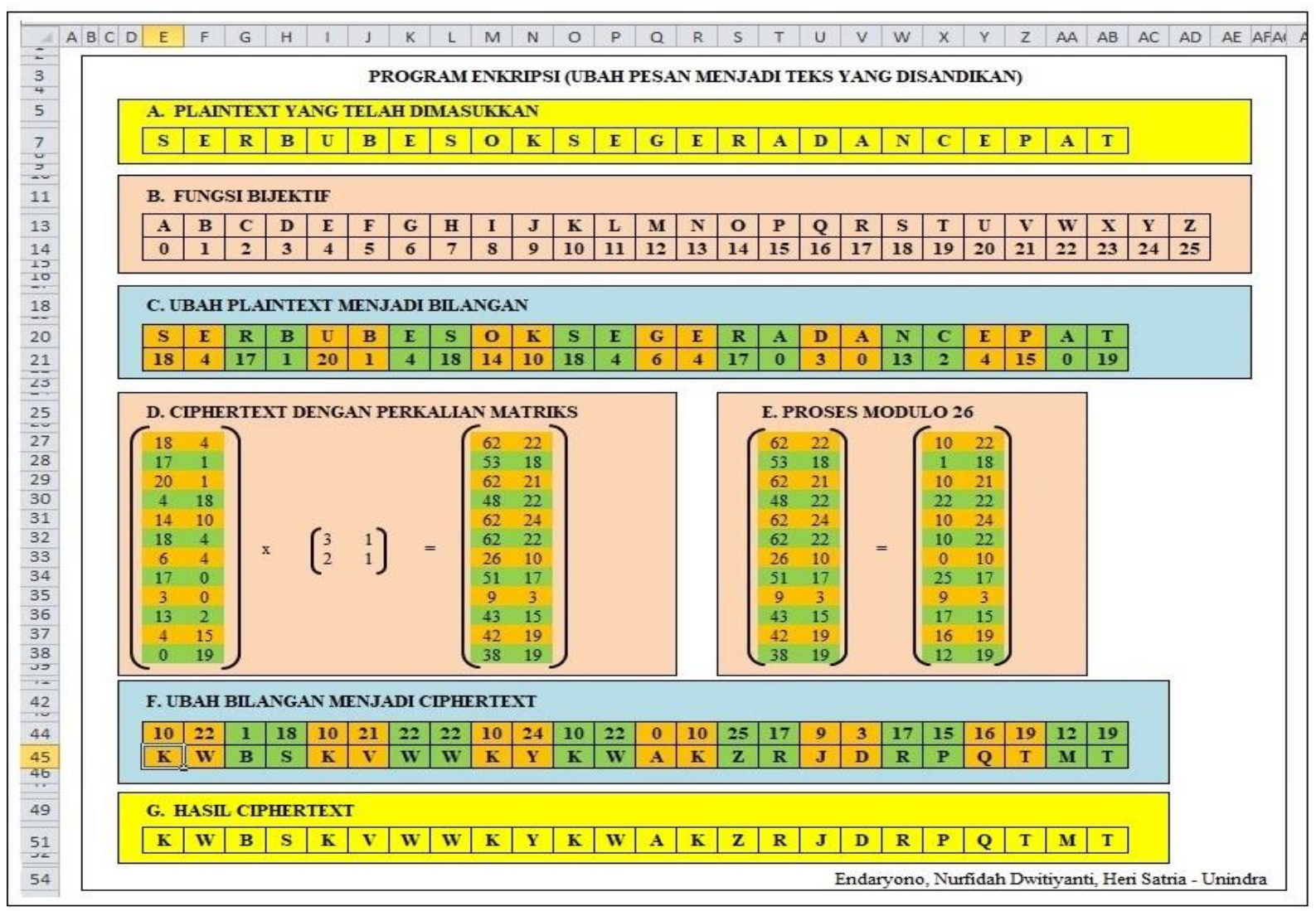

Gambar 2. Langkah Kerja dalam Proses Enkripsi

Penjelasan gambar 2 tentang langkah kerja dalam proses enkripsi sebagai berikut:

a. Plaintext yang telah dimasukkan adalah: SERBUBESOKSEGERADANCEPAT

b. Dibuat fungsi bijektif atau fungsi satusatu, dengan domain himpunan abjad $=$ $\{\mathrm{a}, \mathrm{b}, \ldots, \mathrm{z}\}$ dan kodomain berupa angka modulo $26=\{0,1, \ldots, 25\}$

c. Ubah plaintext menjadi bilangan dengan fungsi bijektif. Formula MS Excel yang digunakan:

E21=LOOKUP(E20;\$E\$13:\$AD\$13;\$E \$14:\$AD\$14)

d. Lakukan perkalian antara matriks plain text dengan matriks kunci dan hasilnya matriks ciphertext atau matriks sandi. Formula excel yang digunakan: $\mathrm{M} 27=(\mathrm{E} 27 * \$ \mathrm{I} \$ 32)+(\mathrm{F} 27 * \$ \mathrm{I} \$ 33)$

e. Lakukan proses modulo 26 pada matriks ciphertext atau matriks sandi. Formula excel yang digunakaan adalah: $\mathrm{X} 27=\mathrm{MOD}(\mathrm{T} 27 ; 26) \mathrm{G}$ f. Ubah bilangan menjad abjad untuk ciphertext. Formula excel yang digunakan:

E45=LOOKUP(E44;\$E\$14:\$AD \$14;\$E \$13:\$AD\$13)

g. Hasil cipher text adalah copy dari point F.Formula excelnya adalah: E50 $=\mathrm{E} 45$

\section{Proses Deskripsi}

Formula matematis dalam proses dekripsi adalah: $\mathrm{P}=\mathrm{CK}^{-1}[6]$

$\mathrm{P}=$ Matriks plaintext atau matriks dari pesan asli

$\mathrm{C}=$ Matriks ciphertext atau matriks pesan yang sudah diacak

$\mathrm{K}^{-1}=$ Invers matriks kunci atau invers matriks key yaitu invers dari matriks kunci yang digunakan dalam proses enkripsi.

Secara lengkap, operasi matematika dalam proses enkripsi sebagai berikut:

$\mathrm{C}_{11}=\left(\mathrm{P}_{11} \cdot \mathrm{K}^{-1}{ }_{11}+\mathrm{P}_{12} \cdot \mathrm{K}^{-1}{ }_{21}\right) \bmod 26$

$\mathrm{C}_{12}=\left(\mathrm{P}_{11} \cdot \mathrm{K}^{-1}{ }_{12}+\mathrm{P}_{12} \cdot \mathrm{K}^{-1}{ }_{22}\right) \bmod 26$ 
$\mathrm{C}_{21}=\left(\mathrm{P}_{21} \cdot \mathrm{K}^{-1}{ }_{11}+\mathrm{P}_{22} \cdot \mathrm{K}^{-1}{ }_{21}\right) \bmod 26$

$\mathrm{C}_{22}=\left(\mathrm{P}_{21} \cdot \mathrm{K}^{-1}{ }_{12}+\mathrm{P}_{22} \cdot \mathrm{K}^{-1}{ }_{22}\right) \bmod 26$

dan seterusnya.

Formula matematis ini diterapkan dalam proses dekripsi metode Hill Cipher sebagai berikut:

1. Masukkan $\mathrm{C}$ pesan sandi (cipher text).

2. Pesan sandi diubah menjadi angka yang nilainya dari 0 sampai dengan 25 atau modulo 26. Pengubahan teks menjadi angka berdasarkan fungsi bijektif.

3. Selanjutnya semua bilangan disusun menjadi blok-blok dan terbentuk matriks dengan ordo $\mathrm{mx} 2$. Hasil dari langkah ini berupa matriks sandi Mc.

4. Masukkan kunci untuk persandian berupa matriks persegi ordo $2 \times 2$. Selanjutnya mtriks ini disebut dengan matriks kunci atau Mk. Matriks kunci selanjutnya diubah menjadi invers matriks kunci atau $\mathbf{M k}^{-1}$

5. Lakukan perkalian antara matriks sandin (Mc) ordo $\mathrm{mx} 2$ dengan invers matriks kunci $\left(\mathbf{M k}^{-\mathbf{1}}\right)$ ordo $2 \times 2$. Hasilnya matriks pesan (Mp) ordo mx2. Dalam persamaan matematika ditulis: $\mathbf{M p}=\mathbf{M c} . \mathbf{M k}^{-1}$.

6. Lakukan operasi aritmatika modulo 26 pada matriks pesan Mp sehingga semua anggota matriks pesan dimulai dari 0 sampai dengan 25.

7. Susun kembali blok-blok pada matriks pesan Mp dalam susunan mendatar atau horizontal.

8. Ubah bilangan-bilangan pada susunan horizontal menjadi abjad dengan menggunakan fungsi bijektif.

Tampilan muka input dan output proses dekripsi dapat dilihat pada gambar 3

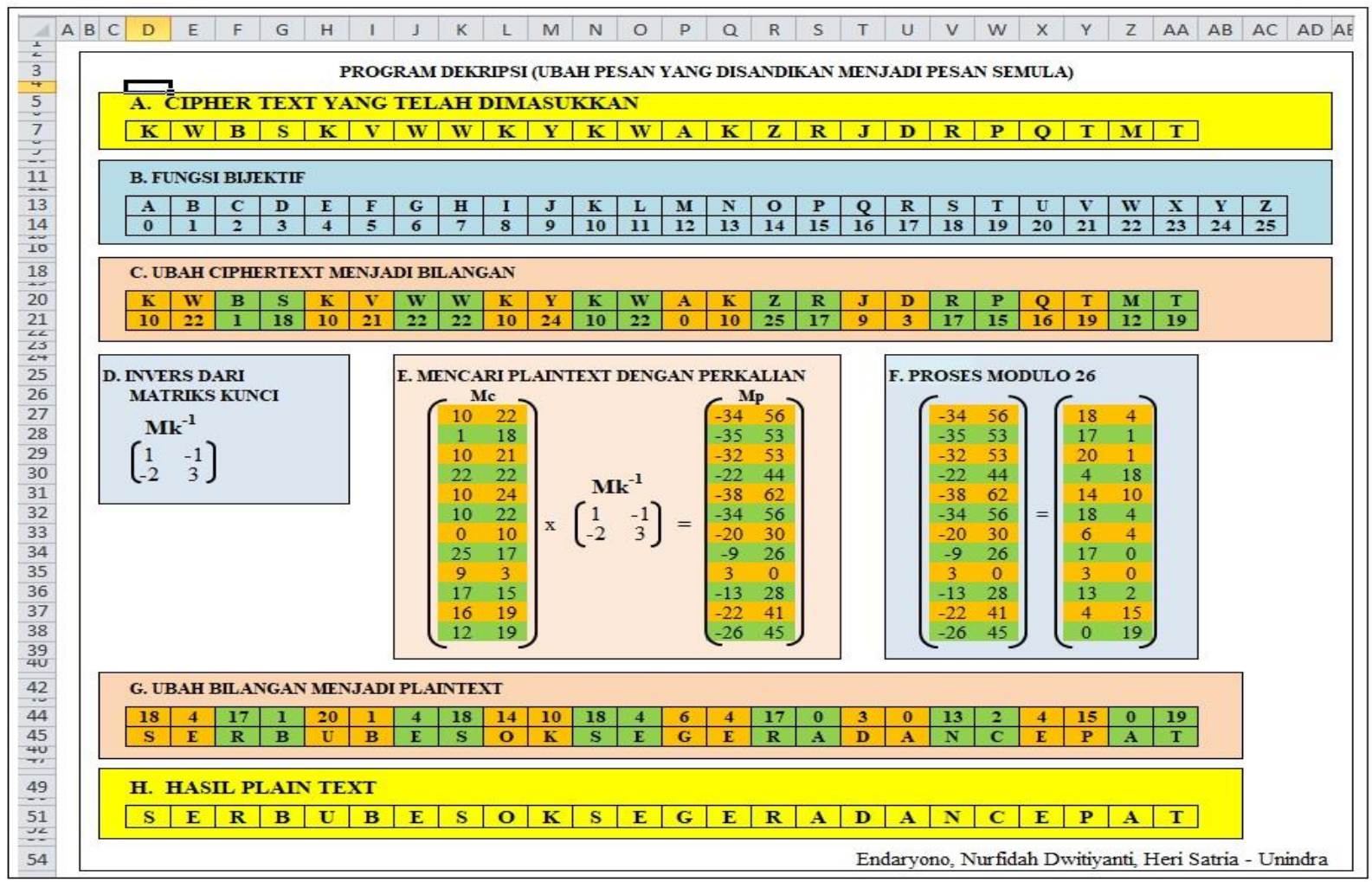

Gambar 3. Langkah kerja dalam proses dekripsi

Penjelasan gambar 3 tentang langkah kerja dalam proses enkripsi sebagai berikut: a. Plaintext yang telah dimasukkan adalah: KWBSKVWWKYKWAKZRJDRPQT MT 
b. Dibuat fungsi bijektif atau fungsi satusatu, dengan domain himpunan abjad $=$ $\{\mathrm{a}, \mathrm{b}, \ldots, \mathrm{z}\}$ dan kodomain berupa angka modulo $26=\{0,1, \ldots, 25\}$

c. Ubah abjad dari pesan sandi (cipher text) menjadi bilangan dengan fungsi bijektif. Formula Excel yang digunakan: D21=LOOKUP(D20;\$D \$13:\$AC\$13;\$ D\$14:\$AC\$14)

d. Lakukan operasi invers matriks kunci atau matriks sandi $\mathbf{M k}$ menjadi $\mathbf{M k}^{-\mathbf{1}}$

e. Lakukan perkalian antara matriks ciphertext dengan invers matriks kunci dan hasilnya matriks pesan (plaintext). Formula excel yang digunakan: $\mathrm{Q} 27=\mathrm{IF}(\$ \mathrm{H} \$ 33=0 ;(\mathrm{K} 27 * \$ \mathrm{~N} \$ 32)+(\mathrm{L} 27 *$ \$N\$33);"')

f. Lakukan proses modulo 26 pada matriks pesan atau matriks plaintext. Formula excel yang digunakaan adalah: Y27 = IF(\$H \$33=0;MOD(V27;26);" )

g. Ubah bilangan menjad abjad untuk plaintext.

Formula excel yang digunakan:
D45=IF $(\$ H \$ 33=0 ;$ LOOKUP(D44;\$D \$ 1 4:\$AC\$14;\$D\$13:\$AC\$13);"")

h. Hasil plaintext adalah copy dari point G.Formula excelnya adalah: D51=D45

\section{Implementasi}

Selanjutnya dilakukan implementasi rancangan simulasi. Pelaksanaan melalui dua halaman aplikasi, yaitu:

a. Halaman input dan output proses enkripsi

b. Halaman input dan output proses enkripsi.

Pada halaman input dan output proses enkripsi pengguna atau user menginputkan isi pesan. Sebelum pengguna memasukkan isi pesan (plaintext) dan belum memasukkan matriks sandi atau matriks kunci, maka halaman pada aplikasi excel belum menampilkan pesan sandi (ciphertext). Tampilan awal sebelum pengguna (user) memasukkan pesan dan kunci dapat dilihat pada gambar 4 .

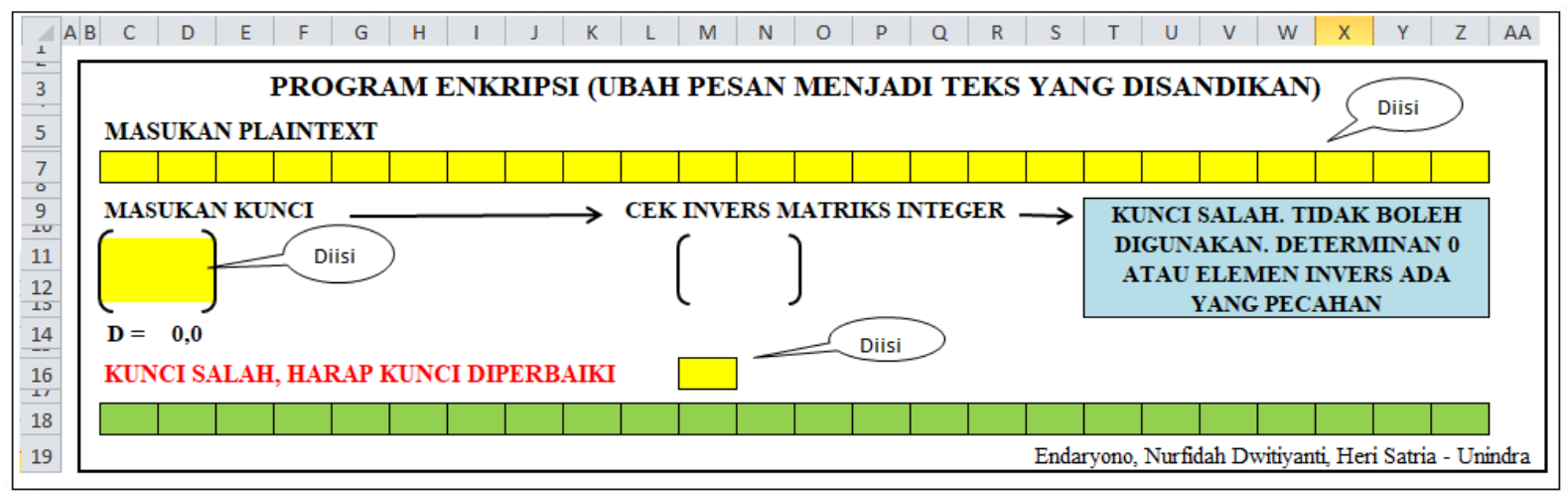

Gambar 4. Tampilan Halaman Input dan Output Proses Enkripsi Sebelum User Memasukkan Kunci

Kemudian pengguna atau user menginputkan pesan dan kunci sandi berupa matriks ordo $2 \times 2$. Aplikasi secara otomatis akan menampilkan pesan yang telah disandikan atau cipher text Tampilan pada aplikasi setelah pengguna atau user memasukkan pesan dan matriks kunci atau matriks asndi dapat dilihat pada gambar 5. 


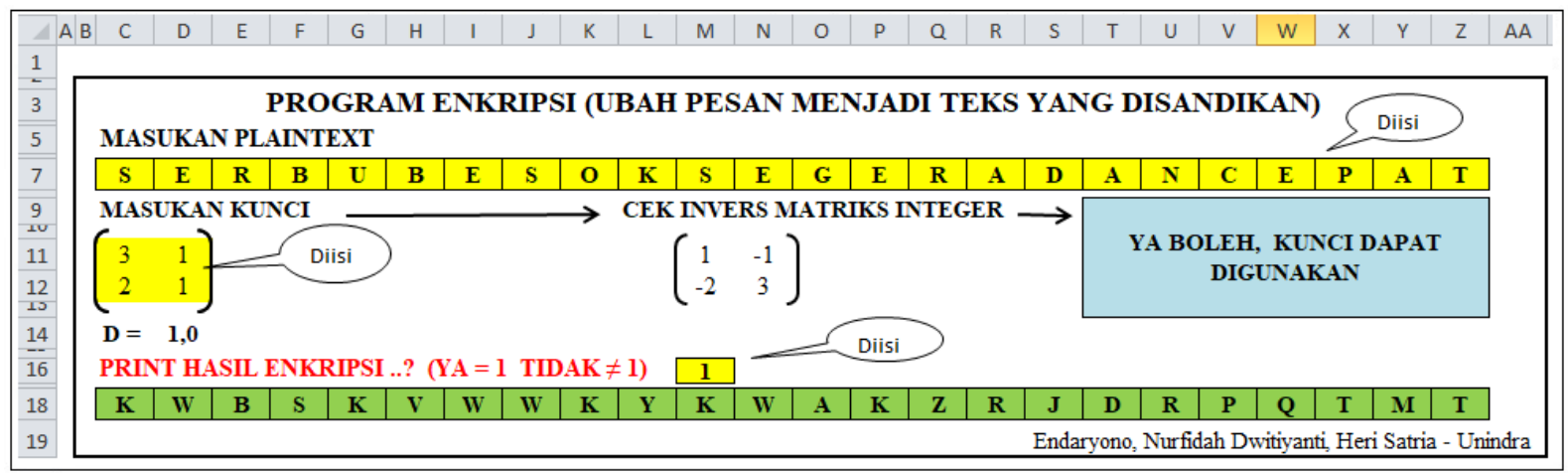

Gambar 5. Tampilan Halaman Proses Enkripsi Setelah User Memasukkan Kunci

Seperti pada pelaksanaan enkripsi, maka dalam pelaksanaan dekripsi, tahap awal, user harus memasukkan pesan yang telah disandikan (ciphertext). Saat user belum menginput pesan sandi dan matriks kunci, aplikasi belum menampilkan hasil atau belum ada respon. Tampilan awal sebelum user memasukkan pesan sandi dan kunci dapat dilihat pada gambar 6

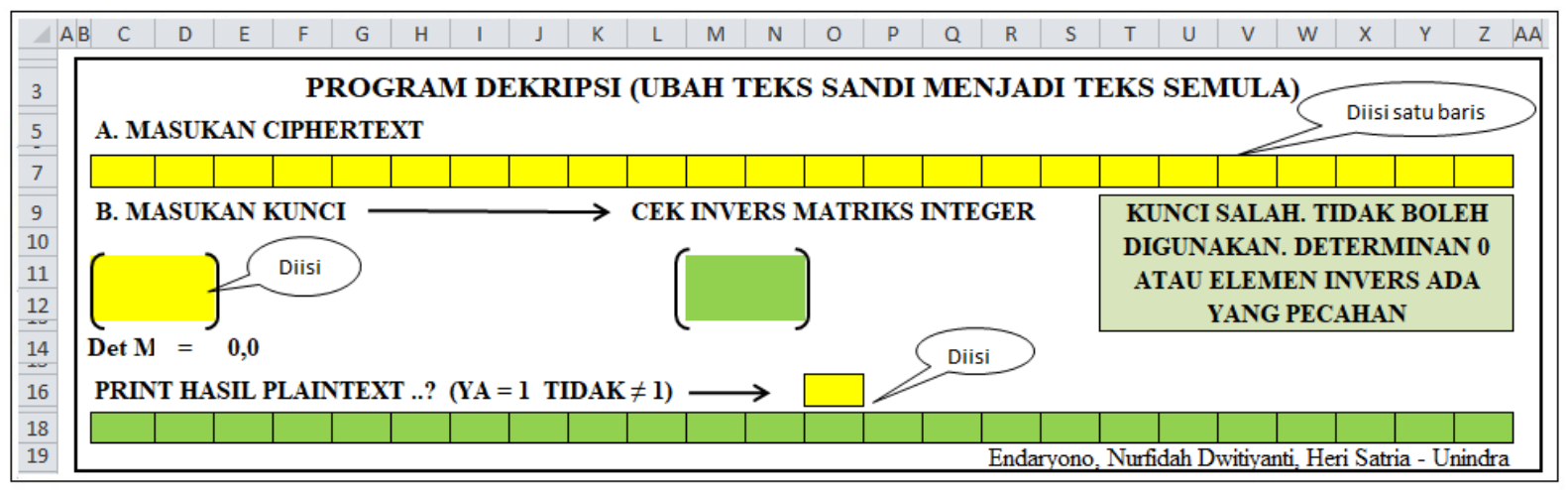

Gambar 6. Tampilan Halaman Proses Dekripsi Sebelum User Memasukkan Kunci

Kemudian pengguna atau user menginputkan pesan sandi dan matriks kunci atau matriks sandi dengan ordo $2 \times 2$. Aplikasi omatis akan menampilkan pesan asli (plaintext). Tampilan pada aplikasi

setelah pengguna atau user memasukkan pesan sandi (plaintext) dan matriks kunci atau matriks sandi dapat dilihat pada gambar 7.

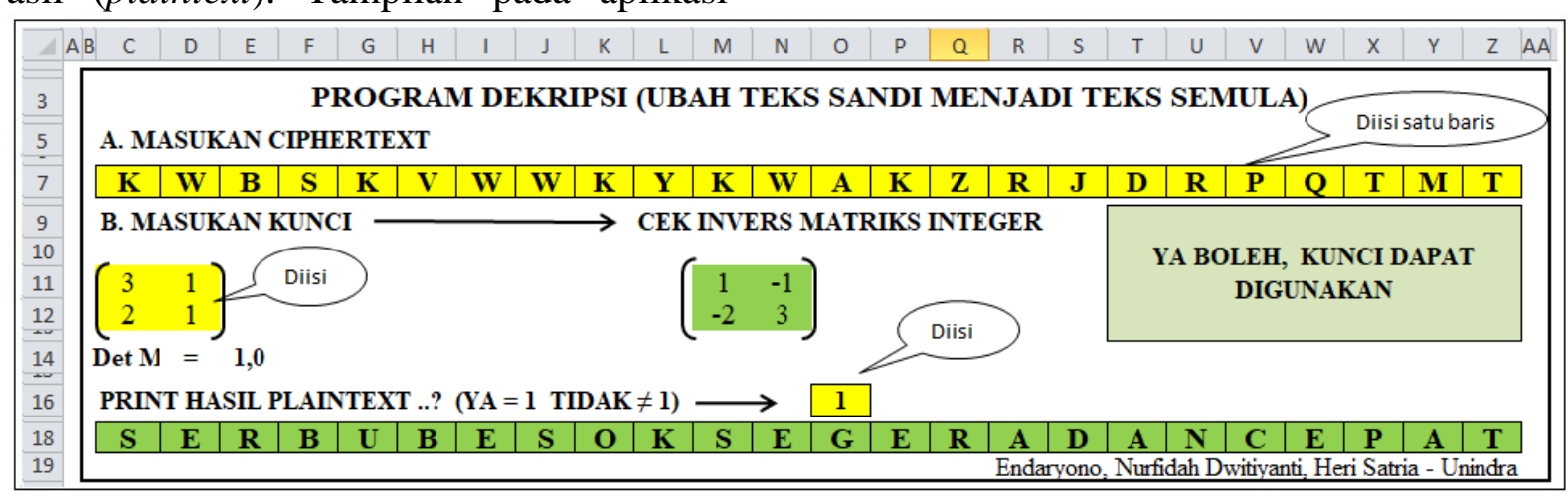

Gambar 7. Tampilan Halaman Proses Deskripsi Setelah User Memasukkan Kunci 
Beberapa catatan tentang penginputan matriks kunci (key matrix) untuk proses pengacakan pesan asli (plain text) adalah:

1. Matriks kunci yang diinputkan adalah matriks persegi ordo $2 \times 2$ dengan jumlah elemen empat.

2. Elemen yang diinputkan harus membentuk matriks invertible atau nonsingular, yaitu matriks yang determinannya tidak nol sehingga memiliki invers matriks.

3. Determinan harus bernilai 1 atau -1 . Jika determinan bernilai selain 1 atau 1 menyebabkan elemen-elemen pada invers matriks bernilai pecahan dan pada rancangan simulasi ini tidak bisa dilakukan perhitungan aritmatika modulo.

4. Persyaratan dalam determinan harus bernilai 1 atau -1 menyebabkan kemungkinan kunci menjadi terbatas.

\section{SIMPULAN}

Berdasarkan hasil dan pembahasan, dapat disimpulkan bahwa uji coba hasil perancangan simulasi metode Hill Cipher dengan menggunakan apikasi Microsoft Excel dapat berjalan dan proses kerja dapat berfungsi dengan baik.

Aplikasi simulasi ini dapat dijadikan sebagai pilihan media pembelajaran kriptografi.

Penelitian ini menggunakan modulo 26 yaitu dari 0 sampai dengan 25 sesuai jumlah abjad atau alphabet dengan matriks kunci atau key matrix untuk persandian yang digunakan adalah matriks persegi dengan ordo $2 \times 2$.

Entri-entri yang diinput untuk elemen matriks kunci harus merupakan bilangan bulat (integer).

Matriks kunci yang diinputkan harus merupakan matriks nonsingular atau matriks yang mempunyai invers. Dengan kata lain, matriks kunci yang diinput tidak boleh memiliki determinan 0 .
Matriks kunci yang diinputkan juga harus memiliki nilai determinan 1 atau -1 agar elemen-elemen pada invers matriks tidak bernilai pecahan.

\section{DAFTAR PUSTAKA}

[1] D. Adhar, "Implementasi Algoritma Des (Data Encryption Standard) Pada Enkripsi Dan Deskripsi Sms Berbasis Android," J. Tek. Inform. Kaputama, vol. 3, no. 2, pp. 53-60, 2019, [Online]. Available: https://jurnal.kaputama.ac.id/index.p $\mathrm{hp} / \mathrm{JTIK} /$ article/view/185.

[2] A. Prayitno and N. Nurdin, "Analisa Dan Implementasi Kriptografi Pada Pesan Rahasia," J. Elektron. Sist. Inf. dan Komput., vol. 3, no. 1, pp. 1-11, 2017, [Online]. Available: nnurdin69@gmail.com.

[3] B. Solihin Hasugian, "Peranan Kriptografi Sebagai Keamanan Sistem Informasi Pada Usaha Kecil Dan Menengah," J. Chem. Inf. Model., vol. 53, no. 9, pp. 16891699, 2019, doi: https://doi.org/10.46576/wdw.v0i53. 269.

[4] P. Nur Arifah and W. A. Basuki, "Implementasi Kriptografi Caesar Chiper," in Seminar Matematika Dan Pendidikan Matematika Uny 2017, 2017, pp. 297-304.

[5] F. Aryani and Yulianis, "Trace Matriks Berbentuk Khusus 2 x 2 Berpangkat Bilangan Bulat Negatif," J. Sains Mat. dan Stat., vol. 4, no. 2, pp. 105-113, 2018.

[6] L. J. Pangaribuan, "Kriptografi Hybrida Agloritma Hill Cipher Dan Rivest Shamir Adleman (RSA) Sebagai Pengembangan Kriptografi Kunci Simetris (Studi Kasus : Nilai Mahasiswa Amik Mbp)," J. Teknol. Inf. Dan Komun., vol. 7, no. 1, pp. 11-26, 2018. 
[7] I. W. Rachmawati and R. Setiawan,

Menggunakan Algoritma Hill "Analisis Gabungan Strategi Memilih Notasi yang Tepat dan Membentuk Masalah yang Setara Dalam Menentukan Sisa Pembagian," J. Pendidik. Mat. dan Mat. Solusi, vol. II, no. 3, pp. 242251, 2018.

[8] D. Laoli, B. Sinaga, and A. S. R. M. Sinaga, "Penerapan Algoritma Hill Cipher Dan Least Significant Bit (LSB) Untuk Pengamanan Pesan Pada Citra Digital," JISKA (Jurnal Inform. Sunan Kalijaga), vol. 4, no. 3 , p. 1, 2020, doi: 10.14421/jiska.2020.43-01.

[9] E. R. Febrianto and E. A. Sarwoko, "Kriptografi Citra Digital Cipher Dan Affine Cipher Berbasis Android," vol. 10, pp. 11-21, 2018.

[10] W. Y. Azhar, S. Supriyadi, and Y. Yanitasari, "Kriptanalisis Hill Cipher Terhadap Known Plaintext Attack Menggunakan Metode Determinan Matriks Berbasis Android," Simetris J. Tek. Mesin, Elektro dan Ilmu Komput., vol. 8, no. 2, p. 579, 2017, doi: 10.24176/simet.v8i2.1535.

[11] Supiyanto, "Implementasi Hill Cipher Pada Citra Menggunakan Koefisien Binomial," Semin. Nas. Inform. 2015 (semnasIF 2015), vol. 2015, no. November, pp. 284-291, 2015. 